\title{
Thermocouple Wire Device
}

National Cancer Institute

\section{Source}

National Cancer Institute. Thermocouple Wire Device. NCI Thesaurus. Code C50270.

A wire designed for temperature acquisition as part of a thermocouple. 